\title{
Short Term Outcome of Urgent Coronary Artery Bypass Grafting (CABG) Surgery
}

\author{
Yousry Shaheen ${ }^{1}$, Mohamed Youssef ${ }^{1}$, Mohamed Saffan ${ }^{1}$, Moataz Rizk ${ }^{1}$, Ashraf Elnahas ${ }^{1}$, Bassem \\ Mofreh $^{1}$, Ahmed Sobhi ${ }^{1}$, Mohamed Elgazar ${ }^{1}$, Sherif Elhendawy ${ }^{2}$, Yosry Thakeb ${ }^{2}$, Ayman Ghoneim ${ }^{3}$, \\ Sameh I Sersar ${ }^{4}$, Mahmoud Elemam ${ }^{1}$ and Mohamed Alassal ${ }^{1,2^{*}}$
}

${ }^{1}$ Benha University Hospitals, Faculty of Medicine, Cardiothoracic surgery department, Egypt

${ }^{2}$ National Heart Institute, Cairo, Egypt

${ }^{3}$ Alazhar University Hospitals, Faculty of Medicine, Cardiothoracic surgery department, Egypt

${ }^{4}$ Mansoura university, Cardiothoracic Surgery Department, Egypt

Received: March 13, 2018; Accepted: April 18, 2018; Published: April 21, 2018

*Corresponding author: Mohamed Abdelwahab Alassal, consultant and assistant professor of cardiothoracic surgery, Benha Faculty of Medicine, Benha, Egypt, Consultant of cardiothoracic surgery in PAMCC, Saudi Arabia, Email: dmohamedabdelwahab@gmail.com

\begin{abstract}
Background and aim of the study: Outcomes of emergency coronary artery bypass grafting (CABG) for acute coronary syndrome (ACS) due to left main coronary (LM) disease remain unclear. This study aims to assess the short term Outcome for patients undergoing Urgent CABG, due to LM disease; as assessed by relief of symptoms and 6 months improvement of EF.

Methods: This study included 60 patients that underwent urgent coronary artery bypass grafting. Patients were divided into three groups according to the pre operative ejection fraction (EF). The three groups were compared regarding preoperative, operative, and postoperative Echo measurement of Ejection fraction and relief of symptoms.

Results: $70 \%$ of our cases were male with mean age of $52.2 \mathrm{yr}$ (range, \pm 7.19 years), no clinical significance between preoperative comorbidities in relation between 3 groups and the postoperative outcome, the risk factors for our patients are Preoperative myocardial infarction (MI), hemodynamic (HD) instability specially in group $\mathrm{C}$ and in turn intraoperative risk is; prolonged Cardiopulmonary bypass time and cross clamp time, while during the intensive care unit stay; postoperative bleeding, MI, prolonged ventilation time and extended ICU stay. The total mortality rate is $8.3 \%$ form our patients. Postoperative echocardiography just before discharge and 6 months later showed significant improvement of EF especially for patient showing preoperative instability and MI.

Conclusion: The present study demonstrated that patients undergoing Urgent CABG have a significant higher preoperative risk especially with myocardial impairment, despite the higher mortality rate $12 \%$, a favorable clinical outcome can be expected if patients survive.

Key words: Urgent CABG, LM disease, ACS, LV impairment.

Abbreviations: ACS: acute coronary syndrome; CABG: Coronary artery bypass surgery; CASS: Coronary Artery Surgery Study; CCS: Canadian Cardiovascular Society; COPD: Chronic obstructive lung disease; DM: Diabetes Mellitus; EF: Ejection fraction; HD: Hemodynamic; HTN: Hypertension; IABP: intra-arotic balloon pump; LAD: left anterior descending artery; LCX: left circumflex artery; LM: left main coronary artery disease; LV: Left ventricle; MI: Myocardial infarction; NYHA: New York Heart Association; PCI: percutaneous coronary intervention; RCA: Right Coronary Artery; WMSI: wall motion score index.
\end{abstract}

\section{Introduction}

Although cardiologists and cardiac surgeons commonly perform urgent CABG in most patients with LMCA stenosis, there is no consensus regarding the ideal interval between the angiographic diagnosis and surgery [1].

Urgent LM surgery is defined as a Procedure required during the same hospitalization in order to minimize chance of further clinical deterioration. Examples of clinical deterioration include but are not limited to: worsening of the symptoms, resistant anginal pain, CHF, progression to acute myocardial infarction (AMI), critical distal LM lesion, requirement of IABP insertion due to chest pain and $\backslash$ or instability, unstable angina (UA) with intravenous (IV) nitroglycerin (NTG) or rest angina [2, 3].

Significant LM disease is defined as the lesion in the main stem of the LCA greater than 50 percent in the coronary angiography or ostial LAD and LCX involvement (equivalent LM) [4, 5].

The indications for revascularization in patients with Severe Coronary Artery Disease are, improvement of prognosis, persistence of symptoms despite medical treatment, Ischemia is of prognostic importance in patients with Severe Coronary Artery Disease, particularly when occurring at low workload. It demonstrated a survival benefit from CABG in patients with LM or Severe three-vessel Coronary Artery Disease, particularly when the proximal LAD coronary artery was involved. Benefits 
were greater in those with severe symptoms, early positive exercise tests, and impaired LV function. Based on the Coronary Artery Surgery Study (CASS) registry, it has been suggested that two important pathophysiological features mitigate against the success of PCI in LM lesions: (1st) up to $80 \%$ of LM disease involves the bifurcation, which is known to be at higher risk of restenosis and (2nd) up to $80 \%$ of LM patients also have multi-vessel Severe Coronary Artery Disease, where CABG offers a survival advantage independent of the presence of LM disease [6].

\section{Patients and Methods}

This study was done in the period from December 2014 to July 2016 in three tertiary centers in Egypt (Benha university hospital, National heart institute and Alazhar university hospitals).

It included 60 patients with significant LM disease or LM equivalent underwent urgent $\mathrm{CABG}$, According to society of thoracic surgeon we chose urgent $\mathrm{CABG}$ in order to minimize the chance of further clinical deterioration: examples include, worsening general condition, sudden chest pain, acute myocardial infarction, intra-aortic balloon pump insertion, and unstable angina with intravenous nitroglycerin or rest angina.

Also included patients with critical distal LM lesion or significant LM disease with ACS. We excluded patient with accompanied mechanical complications post MI like ventricular septum rupture, acute ischemic mitral regurgitation due to papillary muscle rupture or LV free wall rupture. Patients with previous sternotomy or history of open-heart surgery were also excluded.

Table 1: Distribution of the studied cases according to preoperative Ejection Fraction $(n=60)$

\begin{tabular}{|c|c|c|}
\hline EF & No. & \% \\
\hline $50-60 \%$ Group (A) & 26 & 43.3 \\
\hline $40-49 \%$ Group (B) & 14 & 23.3 \\
\hline $30-39 \%$ Group (C) & 20 & 33.3 \\
\hline
\end{tabular}

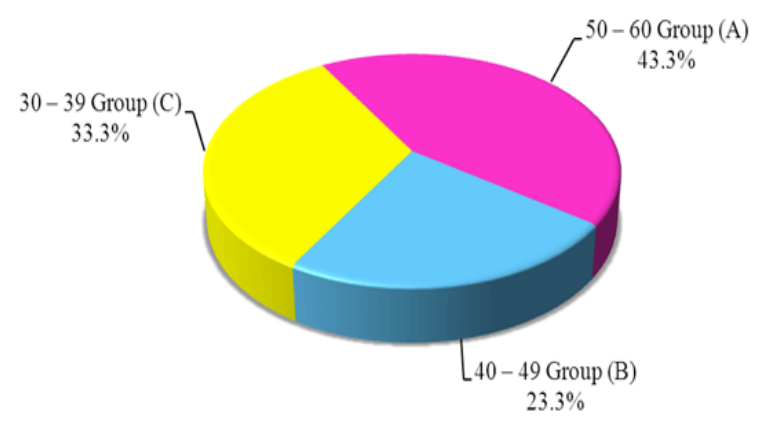

Figure 1: Distribution of the studied cases according to preoperative Ejection Fraction

Patients were divided into three groups according to their Ejection fraction (Table 1, Figure 1). The three groups were compared regarding preoperative, operative, and postoperative data. Urgent conventional CABG was performed under antegrade cardioplegic arrest with cardiopulmonary bypass. We used the left internal thoracic artery (LITA) to LAD, saphenous vein (SVG) to $\mathrm{OM} \pm$ Diagonal and $\mathrm{RCA}$, and 6 patients we used radial artery (RA) as a conduit to tight $\mathrm{OM}$ lesion.

\section{Results}

The male gender was 42 cases (70\%) while the female was 18 cases (30\%), with mean age of 52.21 \pm 7.19 (Table 2).

Baseline demographic data and risk factors prevalence of the study population shown in table 3 .

The preoperative data showed that the comorbidities among the three groups were not significant (Table 3 and Figure 2).

Table 2: gender distribution and mean age of our patients

\begin{tabular}{|c|c|}
\hline Demographic data & Total $(\mathbf{N = 6 0 )}$ \\
\hline Sex & \\
\hline Male & $42(70 \%)$ \\
\hline Female & $18(30 \%)$ \\
\hline Age (years) Range $[$ Mean $\pm S D]$ & $45-65[52.21 \pm 7.19]$ \\
\hline
\end{tabular}

Preoperative symptomatology distribution showed statistical significance as recent MI is higher in-group C, $11 \backslash 17$ patients who had previous MI with significant P-value of 0.002 .

According to New York Heart Association classification (NYHA), group A has 12 patients with NYHA class I while 1 patient only in-group $C$ with P-value 0.009 . There are zero patients from group A with NYHA class III while 7 patients in group B and 10 in group $\mathrm{C}$ with significant $\mathrm{P}$-value of $<0.001$ (Table 4 , Figure 3).

According to Canadian Cardiovascular Society (CCS) grading of angina pectoris there is significant difference with CCS Class III and class IV as there with group 3 there are 7 patients with class III and 11 with class IV.

There were 12 patients that came with hemodynamic instability 9 of them from group C while 2 from group B and 1 from group A with P-value $=0.001$ showing statistical significance.

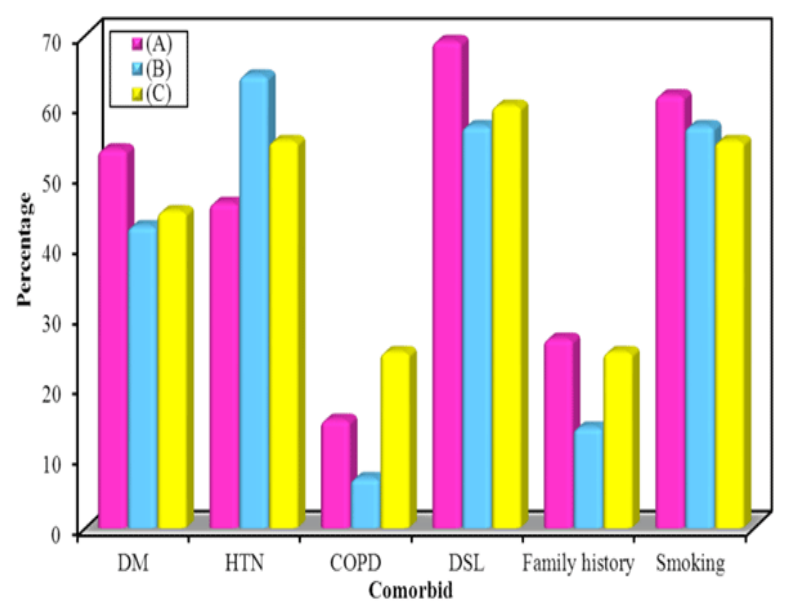

Figure 2: Preoperative co-morbidities according to 3 groups 
Table 3: Preoperative co-morbidities according to 3 groups

\begin{tabular}{|c|c|c|c|c|c|c|c|c|c|c|}
\hline & & & \multicolumn{6}{|c|}{$\mathbf{E F}$} & \multirow{3}{*}{$\chi^{2}$} & \multirow{3}{*}{$\mathbf{p}$} \\
\hline & \multicolumn{2}{|c|}{$\begin{array}{c}\text { Total } \\
(n=60)\end{array}$} & \multicolumn{2}{|c|}{$\begin{array}{c}(A) \\
(n=26)\end{array}$} & \multicolumn{2}{|c|}{$\begin{array}{c}\text { (B) } \\
(n=14)\end{array}$} & \multicolumn{2}{|c|}{$\begin{array}{c}(C) \\
(n=20)\end{array}$} & & \\
\hline & No. & $\%$ & No. & $\%$ & No. & $\%$ & No. & $\%$ & & \\
\hline DM & 29 & 48.3 & 14 & 53.8 & 6 & 42.9 & 9 & 45.0 & 0.574 & 0.751 \\
\hline HTN & 32 & 53.3 & 12 & 46.2 & 9 & 64.3 & 11 & 55.0 & 1.236 & 0.539 \\
\hline COPD & 10 & 16.7 & 4 & 15.4 & 1 & 7.1 & 5 & 25.0 & 1.765 & $\mathrm{MCp}=0.414$ \\
\hline Hyperlipidemia & 38 & 63.3 & 18 & 69.2 & 8 & 57.1 & 12 & 60.0 & 0.716 & 0.699 \\
\hline Family history & 14 & 23.3 & 7 & 26.9 & 2 & 14.3 & 5 & 25.0 & 0.824 & $\mathrm{MCp}=0.735$ \\
\hline Smoking & 35 & 58.3 & 16 & 61.5 & 8 & 57.1 & 11 & 55.0 & 0.209 & 0.901 \\
\hline
\end{tabular}

$\chi 2, \mathrm{p}: \chi^{2}$ and $\mathrm{p}$ values for Chi square test

${ }^{\mathrm{MC}} \mathrm{p}$ : $\mathrm{p}$ value for Monte Carlo for Chi square test

Table 4: Preoperative symptomatology distribution according to the groups

\begin{tabular}{|c|c|c|c|c|c|c|c|c|c|c|}
\hline & \multirow{2}{*}{\multicolumn{2}{|c|}{$\begin{array}{c}\text { Total } \\
(n=60)\end{array}$}} & \multicolumn{6}{|c|}{ EF } & \multirow{3}{*}{$\chi^{2}$} & \multirow{3}{*}{$\mathbf{p}$} \\
\hline & & & \multicolumn{2}{|c|}{$\begin{array}{c}(A) \\
(n=26)\end{array}$} & \multicolumn{2}{|c|}{$\begin{array}{c}(B) \\
(n=14)\end{array}$} & \multicolumn{2}{|c|}{$\begin{array}{c}(C) \\
(n=20)\end{array}$} & & \\
\hline & No. & $\%$ & No. & $\%$ & No. & $\%$ & No. & $\%$ & & \\
\hline AMI & 17 & 28.3 & 2 & 7.69 & 4 & 28.57 & 11 & 55 & $12.460^{*}$ & $0.002^{*}$ \\
\hline \multicolumn{11}{|l|}{ NYHA } \\
\hline I & 17 & 28.3 & 12 & 46.15 & 4 & 28.57 & 1 & 5 & $9.429^{*}$ & $0.009^{*}$ \\
\hline II & 11 & 18.3 & 1 & 3.85 & 1 & 7.14 & 9 & 45 & $12.587^{*}$ & ${ }^{\mathrm{MC}} \mathrm{p}=0.001^{*}$ \\
\hline III & 17 & 28.3 & 0 & 0.0 & 7 & 50.0 & 10 & 50.0 & $18.140^{*}$ & $<0.001^{*}$ \\
\hline \multicolumn{11}{|l|}{ CCS } \\
\hline $\mathbf{I}$ & 15 & 25 & 9 & 34.62 & 4 & 28.57 & 2 & 10.0 & 3.777 & 0.151 \\
\hline II & 6 & 10 & 4 & 15.38 & 2 & 14.29 & 0 & 0.0 & 3.553 & ${ }^{\mathrm{MC}} \mathrm{p}=0.148$ \\
\hline III & 10 & 16.7 & 0 & 0 & 3 & 21.43 & 7 & 35.0 & $11.255^{*}$ & ${ }^{\mathrm{MC}} \mathrm{p}=0.001^{*}$ \\
\hline IV & 13 & 21.7 & 0 & 0 & 2 & 14.29 & 11 & 55.0 & $20.535^{*}$ & ${ }^{\mathrm{MC}} \mathrm{p}<0.001^{*}$ \\
\hline $\begin{array}{c}\text { HD } \\
\text { instability }\end{array}$ & 12 & 20.0 & 1 & 3.85 & 2 & 14.29 & 9 & 45.0 & $11.524^{*}$ & ${ }^{\mathrm{MC}} \mathrm{p}=0.001^{*}$ \\
\hline $\begin{array}{l}\text { Needs for } \\
\text { intropes }\end{array}$ & 11 & 18.3 & 0 & 0 & 2 & 14.29 & 9 & 45.0 & $15.359 *$ & ${ }^{\mathrm{MC}} \mathrm{p}<0.001^{*}$ \\
\hline $\begin{array}{l}\text { Needs for } \\
\text { IABP }\end{array}$ & 6 & 10.0 & 1 & 3.85 & 1 & 7.14 & 4 & 20.0 & 3.034 & ${ }^{\mathrm{MC}} \mathrm{p}=0.215$ \\
\hline \multicolumn{11}{|c|}{$\begin{array}{l}\chi 2, p: \chi 2 \text { and } p \text { values for Chi square test } \\
\text { Mc } p \text { : } p \text { value for Monte Carlo for Chi square test } \\
\text { *: Statistically significant at } p \leq 0.05 \\
\text { N.B there were } 15 \text { patients free of symptoms }\end{array}$} \\
\hline
\end{tabular}

Citation: Alassal MD, Shaheen Y, Youssef MD, Saffan MD, Moataz R, et al. (2018) Short Term Outcome of Urgent Coronary Artery Page 3 of 10 Bypass Grafting (CABG) Surgery. Cardiovascular Thoracic Surgery 3(2):1-10. DOI: 10.15226/2573-864X/3/2/00138 
Patients needed inotropic support preoperatively were 12 patients 9 from Group C, 2 from group B and no one from group A needed inotropic support with $\mathrm{P}$-value $<0.001$ showing statistical significance.

Patients needing preoperative IABP were 6 patients 4 from group C, 1 from group B and 1 from group A with P-value 0.215 (Table 4).

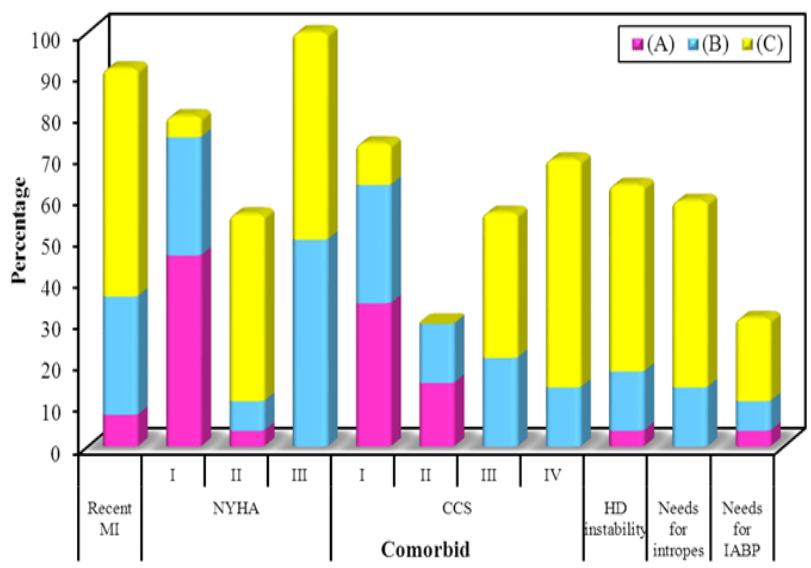

Figure 3: Preoperative symptomatology distribution according to groups
Bypass time and Clamp time were higher with group $C$ while the number of grafts used didn't show significant difference between all groups (Table 5, Figure 4).

Mean Ventilation time and ICU stay were higher with group C.

Total mortality was 5 patients which is $12 \%$ of all patients, 1 patient died intraoperative and 4 patients died during the ICU period; 4 patients were from group $C$ and 1 patient from group $B$ with P-value 0.025 (Table 7, Figure 6).

Postoperative complications didn't show statistically difference between the 3 groups (Table 7, Figure 6).

The inotropic support postoperatively showed statistical significance, as there were $34 \backslash 60$ patients on inotropic support postoperatively; 16 patients from group C, 9 patients from group $\mathrm{B}$ and 9 from group A with P-value 0.003. Showing statistical significance

IABP was used postoperatively in $11 \backslash 60,7$ from group $C$ and 2 from group B and 2 from group A with P-value 0.004. Showing statistical significance

Reopened cases were $3 ; 2$ patients from group $C$ reopened due to post operative bleeding and 1 patient from group $\mathrm{B}$ reopened due to postoperative MI to recheck the grafts (Table 8, Figure 7).

Postoperative echocardiography follow up was done before discharge and 6 months postoperatively being compared to baseline ECHO done prior to surgery to respective to the 3 groups and showed statistically significant difference (Table 9, Figure 8).

Table 5: Intraoperative data according to EF

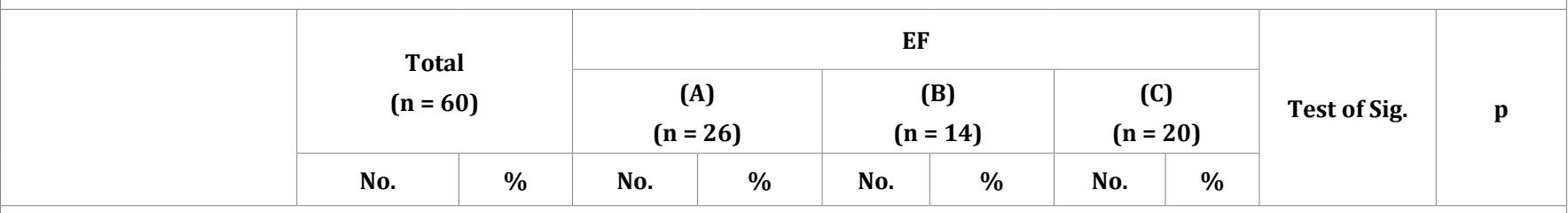

No. of distal grafts anastomosis

\begin{tabular}{|c|c|c|c|c|c|c|c|c|c|c|}
\hline $2 \mathrm{G}$ & 12 & 20 & 6 & 23.08 & 3 & 21.43 & 3 & 15 & \multirow{3}{*}{$\begin{array}{c}\chi^{2}= \\
1.268\end{array}$} & \multirow{3}{*}{$\begin{array}{l}{ }^{\mathrm{MC}} \mathrm{p}= \\
0.907\end{array}$} \\
\hline $3 G$ & 32 & 53.3 & 12 & 46.15 & 8 & 57.14 & 12 & 60 & & \\
\hline $4 \mathrm{G}$ & 16 & 26.7 & 8 & 30.77 & 3 & 21.43 & 5 & 25 & & \\
\hline $\begin{array}{l}\text { Cardiopulmonary bypass } \\
\text { time (СРB) (min.) }\end{array}$ & \multicolumn{2}{|c|}{$60-213$} & \multicolumn{2}{|c|}{$60-120$} & \multicolumn{2}{|c|}{$60-170$} & \multicolumn{2}{|c|}{$90-213$} & & \\
\hline
\end{tabular}

$\chi^{2}, \mathrm{p}: \chi^{2}$ and $\mathrm{p}$ values for Chi square test

${ }^{\mathrm{MC}} \mathrm{p}$ : $\mathrm{p}$ value for Monte Carlo for Chi square test

Regarding the 26 patients of group A; the pre-discharge echo

$20 \backslash 26$ patients remained with EF of $50-60 \%$ while $6 \backslash 26$ patients had decreased EF.

After 6 months; 4 patients regained the EF $50-60 \%$ total $(24 / 26)$ while 2 of them remained with EF less than $50-60 \%$ (Table 10, Figure 9).

In-group B patients; the pre-discharge echo showed
$5 \backslash 13$ cases EF increased to $50-60 \%$ and $7 \backslash 13$ remained with $\mathrm{EF}$ of $40-49 \%$ while $1 \backslash 13$ decreased to $30-39 \%$,

6 months later $4 \backslash 13$ patients showed EF of $50-60 \%$, and 1patient of the increased EF decreased again to $40-49 \%$ and the 2 patients, which showed EF $30-39 \%$, increased to $40-49 \%$ (Table 11, Figure 10).

In group C; the pre-discharge echo showed $8 \backslash 17$ patients with increased EF while $8 \backslash 17$ patients remained with EF of $30-39 \%$, 


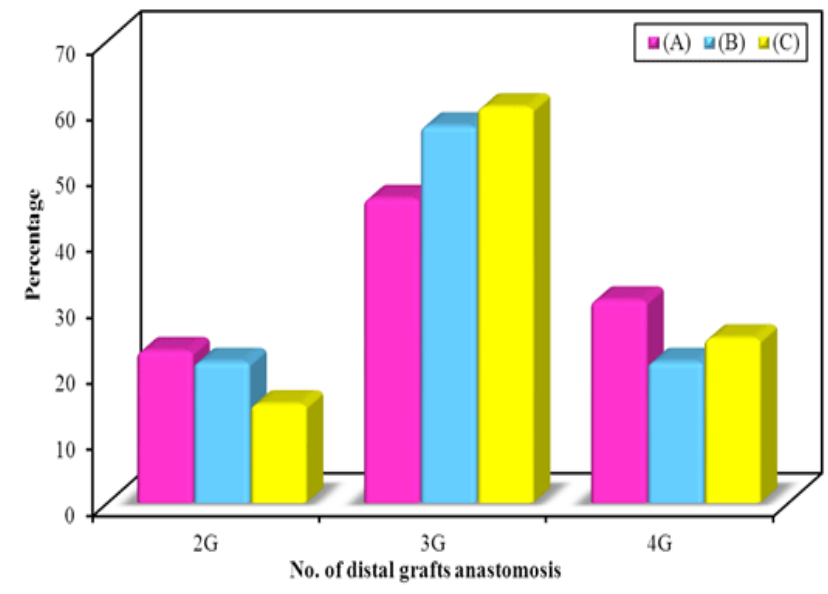

Figure 4: Intraoperative data according to EF

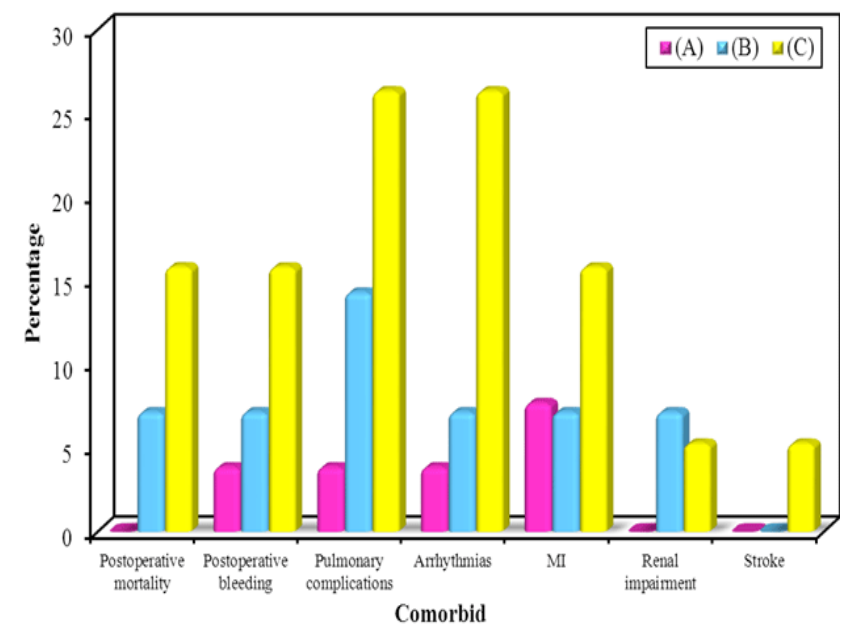

Figure 6: Postoperative Complications according of all patients acc. to 3 groups

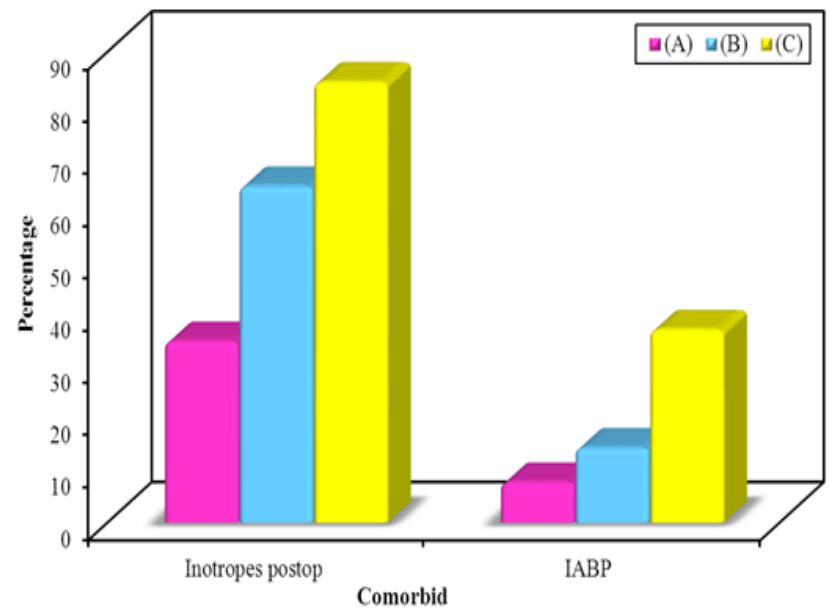

Figure 5: Post op. Data According of all patients acc. to 3 groups (NB: 1 patient died intraoperative)

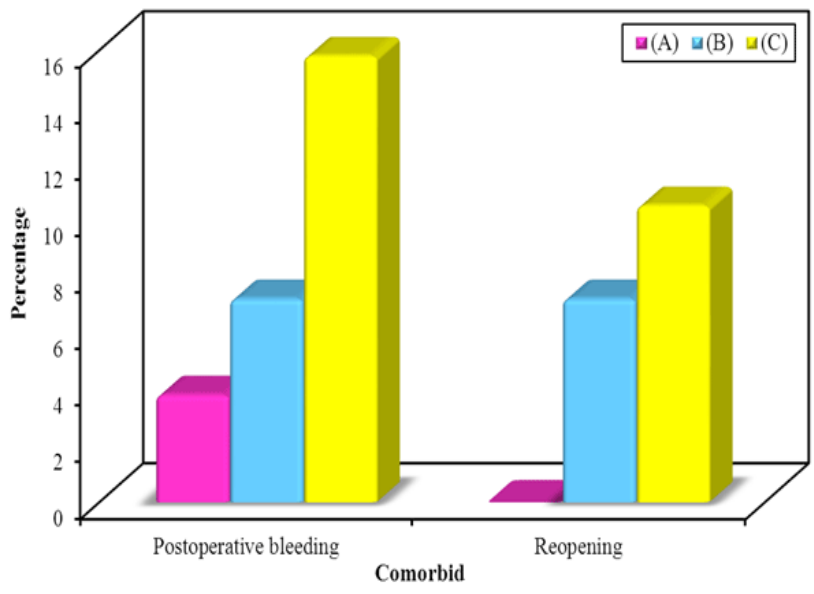

Figure 7: Postoperative Reopening

Table 6: Post op. Data According of all patients acc. to 3 groups

\begin{tabular}{|c|c|c|c|c|c|c|c|c|c|c|}
\hline & & & \multicolumn{6}{|c|}{$\mathbf{E F}$} & \multirow{3}{*}{ Test of Sig. } & \multirow{3}{*}{$\mathbf{p}$} \\
\hline & \multicolumn{2}{|c|}{$\begin{array}{c}\text { Total } \\
(n=59)\end{array}$} & \multicolumn{2}{|c|}{$\begin{array}{c}(A) \\
(n=26)\end{array}$} & \multicolumn{2}{|c|}{$\begin{array}{c}\text { (B) } \\
(n=14)\end{array}$} & \multicolumn{2}{|c|}{$\begin{array}{c}(C) \\
(n=19)^{\#}\end{array}$} & & \\
\hline & No. & $\%$ & No. & $\%$ & No. & $\%$ & No. & $\%$ & & \\
\hline Inotropes postop & 34 & 57.6 & 9 & 34.62 & 9 & 64.29 & 16 & 84.21 & $\chi^{2}=11.391^{*}$ & $0.003^{*}$ \\
\hline IABP & 11 & 18.6 & 2 & 7.69 & 2 & 14.29 & 7 & 36.84 & $\chi^{2}=5.803^{*}$ & ${ }^{M c} p=0.044^{*}$ \\
\hline Mean Ventilation time & \multicolumn{2}{|c|}{$6-168$} & \multicolumn{2}{|c|}{$6-30$} & \multicolumn{2}{|c|}{$9-50$} & \multicolumn{2}{|c|}{$9-168$} & & \\
\hline ICU stay & \multicolumn{2}{|c|}{$2-12$} & \multicolumn{2}{|c|}{$2-3$} & \multicolumn{2}{|c|}{$2-4$} & \multicolumn{2}{|c|}{$5-12$} & & \\
\hline $\begin{array}{l}\chi^{2}, p: \chi^{2} \text { and } p \text { values for } \\
{ }^{\mathrm{Mc}} \mathrm{p} \text { : } \mathrm{p} \text { value for Monte } \mathrm{C} \\
\text { *: Statistically significan }\end{array}$ & $\begin{array}{l}\text { squar } \\
\text { or Chi } \\
\leq 0.0\end{array}$ & e test & & & & & & & & \\
\hline
\end{tabular}




\begin{tabular}{|c|c|c|c|c|c|c|c|c|c|c|}
\hline & \multirow{2}{*}{\multicolumn{2}{|c|}{$\begin{array}{c}\text { Total } \\
(n=59)\end{array}$}} & \multicolumn{6}{|c|}{$\mathbf{E F}$} & \multirow{3}{*}{ Test of Sig. } & \multirow{3}{*}{$\mathbf{p}$} \\
\hline & & & \multicolumn{2}{|c|}{$\begin{array}{c}(A) \\
(n=26)\end{array}$} & \multicolumn{2}{|c|}{$\begin{array}{c}\text { (B) } \\
(n=14)\end{array}$} & \multicolumn{2}{|c|}{$\begin{array}{c}\text { (C) } \\
(n=19)^{\#}\end{array}$} & & \\
\hline & No. & $\%$ & No. & $\%$ & No. & $\%$ & No. & $\%$ & & \\
\hline Postoperative mortality & 4 & 6.8 & 0 & 0 & 1 & 7.14 & 3 & 15.8 & $\chi^{2}=4.334$ & ${ }^{\mathrm{MC}} \mathrm{p}=0.077$ \\
\hline Postoperative bleeding & 5 & 8.5 & 1 & 3.85 & 1 & 7.14 & 3 & 15.79 & $\chi^{2}=1.979$ & ${ }^{\mathrm{MC}} \mathrm{p}=0.429$ \\
\hline Pulmonarycomplications & 8 & 13.6 & 1 & 3.85 & 2 & 14.29 & 5 & 26.32 & $\chi^{2}=4.627$ & ${ }^{\mathrm{MC}} \mathrm{p}=0.097$ \\
\hline Arrhythmias & 7 & 11.9 & 1 & 3.85 & 1 & 7.14 & 5 & 26.32 & $\chi^{2}=4.855$ & ${ }^{\mathrm{MC}} \mathrm{p}=0.066$ \\
\hline MI & 6 & 10.2 & 2 & 7.69 & 1 & 7.14 & 3 & 15.79 & $\chi^{2}=0.995$ & ${ }^{\mathrm{MC}} \mathrm{p}=0.649$ \\
\hline Renal Dysfunction & 2 & 3.4 & 0.0 & 0.0 & 1 & 7.14 & 1 & 5.26 & $\chi^{2}=2.121$ & ${ }^{\mathrm{MC}} \mathrm{p}=0.308$ \\
\hline Stroke & 1 & 1.7 & 0.0 & 0.0 & 0 & 0.0 & 1 & 5.26 & $\chi^{2}=2.016$ & ${ }^{\mathrm{MC}} \mathrm{p}=0.559$ \\
\hline
\end{tabular}

Table 8: Postoperative Reopening

\begin{tabular}{|c|c|c|c|c|c|c|c|c|c|c|}
\hline & & & \multicolumn{6}{|c|}{$\mathbf{E F}$} & \multirow{3}{*}{$\chi^{2}$} & \multirow{3}{*}{$\mathbf{p}$} \\
\hline & \multicolumn{2}{|c|}{$\begin{array}{c}\text { Total } \\
(n=59)\end{array}$} & \multicolumn{2}{|c|}{$\begin{array}{c}(A) \\
(n=26)\end{array}$} & \multicolumn{2}{|c|}{$\begin{array}{c}\text { (B) } \\
(n=14)\end{array}$} & \multicolumn{2}{|c|}{$\begin{array}{c}\text { (C) } \\
(n=19)\end{array}$} & & \\
\hline & No. & $\%$ & No. & $\%$ & No. & $\%$ & No. & $\%$ & & \\
\hline Postoperative bleeding & 5 & 8.5 & 1 & 3.8 & 1 & 7.2 & 3 & 15.8 & 1.979 & 0.428 \\
\hline Reopening & 3 & 5.1 & 0 & 0 & 1 & 7.2 & 2 & 10.5 & 2.84 & 0.246 \\
\hline
\end{tabular}

Table 9: Postoperative before discharge and 6 Months follow up According of all patients acc. to 3 groups

\begin{tabular}{|c|c|c|c|c|c|c|c|c|c|c|}
\hline & & & \multicolumn{6}{|c|}{$\mathbf{E F}$} & \multirow{3}{*}{$\chi^{2}$} & \multirow{3}{*}{${ }^{\mathrm{MC}} \mathbf{P}$} \\
\hline & \multicolumn{2}{|c|}{$\begin{array}{c}\text { Total } \\
(n=55)\end{array}$} & \multicolumn{2}{|c|}{$\begin{array}{c}\text { (A) } \\
(n=26)\end{array}$} & \multicolumn{2}{|c|}{$\begin{array}{c}\text { (B) } \\
(n=13)^{\$}\end{array}$} & \multicolumn{2}{|c|}{$\begin{array}{c}(C) \\
(n=16)^{\#}\end{array}$} & & \\
\hline & No. & $\%$ & No. & $\%$ & No. & $\%$ & No. & $\%$ & & \\
\hline \multicolumn{11}{|c|}{ Postop before Discharge } \\
\hline $50-60$ & 27 & 49.1 & 20 & 76.92 & 5 & 38.46 & 2 & 12.5 & \multirow{3}{*}{$23.384^{*}$} & \multirow{3}{*}{$<0.001^{*}$} \\
\hline $40-49$ & 17 & 30.9 & 4 & 15.38 & 7 & 53.85 & 6 & 37.5 & & \\
\hline $30-39$ & 11 & 20.0 & 2 & 7.69 & 1 & 7.69 & 8 & 50.0 & & \\
\hline \multicolumn{11}{|c|}{6 months Follow up } \\
\hline $50-60$ & 30 & 54.5 & 24 & 92.31 & 4 & 30.77 & 2 & 12.5 & \multirow{3}{*}{$34.606^{*}$} & \multirow{3}{*}{$<0.001^{*}$} \\
\hline $40-49$ & 21 & 38.2 & 1 & 3.85 & 9 & 69.23 & 11 & 68.8 & & \\
\hline $30-39$ & 4 & 7.3 & 1 & 3.85 & 0 & 0.0 & 3 & 18.8 & & \\
\hline \multicolumn{11}{|c|}{$\chi^{2}, \mathrm{p}: \chi^{2}$ and $\mathrm{p}$ values for Chi square test } \\
\hline \multicolumn{11}{|c|}{${ }^{\mathrm{MC}} \mathrm{p}$ : $\mathrm{p}$ value for Monte Carlo for Chi square test } \\
\hline \multicolumn{11}{|c|}{$*$ : Statistically significant at $\mathrm{p} \leq 0.05$} \\
\hline
\end{tabular}

Citation: Alassal MD, Shaheen Y, Youssef MD, Saffan MD, Moataz R, et al. (2018) Short Term Outcome of Urgent Coronary Artery Page 6 of 10 Bypass Grafting (CABG) Surgery. Cardiovascular Thoracic Surgery 3(2):1-10. DOI: 10.15226/2573-864X/3/2/00138 


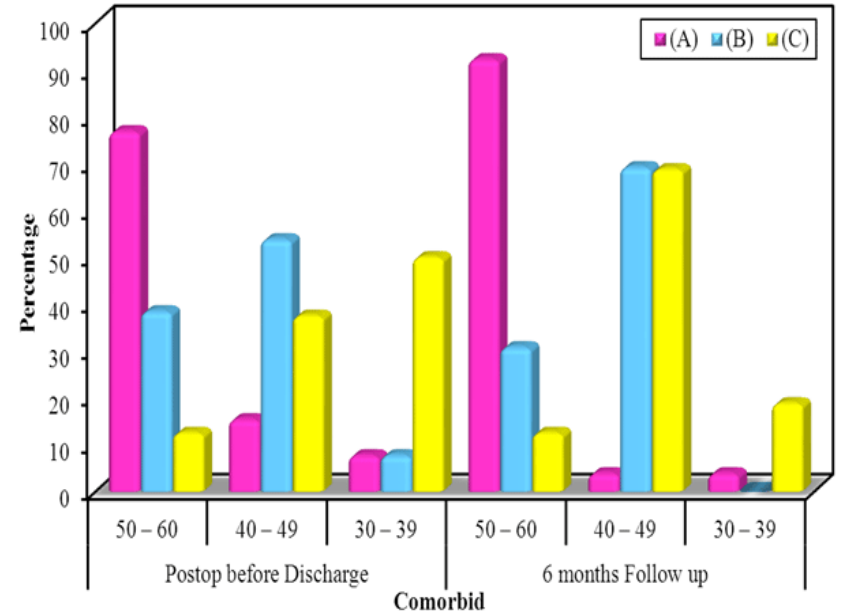

Figure 8: Postoperative before discharge and 6 Months follow up According of all patients acc. to 3 groups NB there are 3 patients died in hospital

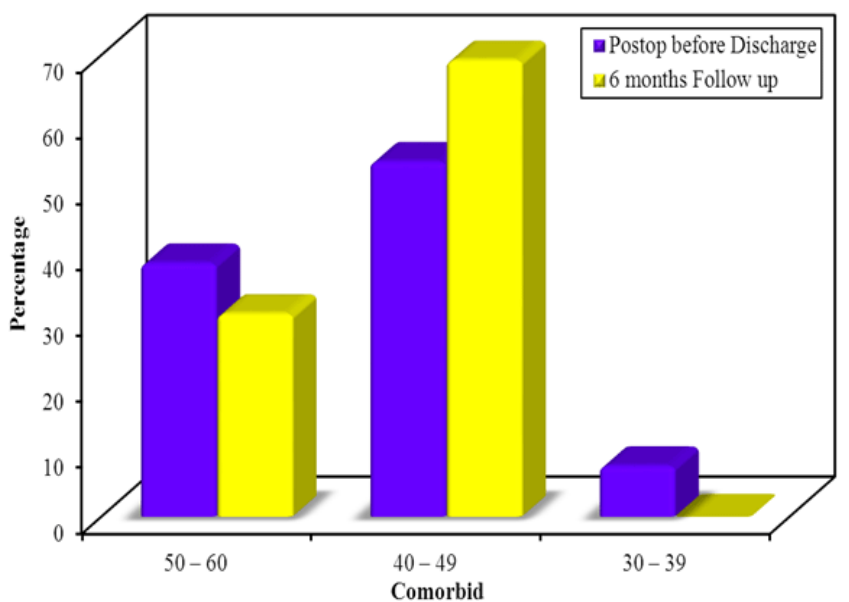

Figure 10: Postoperative and 6 Months follow up According of all patients acc. to group B

Table 10: Postoperative and 6 Months follow up According of all patients acc. to group

A

\begin{tabular}{|c|c|c|c|c|}
\multirow{2}{*}{ Group A } & \multicolumn{2}{|c|}{ Postop before Discharge } & \multicolumn{2}{c|}{$\mathbf{6}$ months Follow up } \\
\cline { 2 - 5 } & No. & \% & No. & \% \\
\hline $50-60$ & 20 & 76.92 & 24 & 92.31 \\
\hline $40-49$ & 4 & 15.38 & 1 & 3.85 \\
\hline $30-39$ & 2 & 7.69 & 1 & 3.85 \\
\hline
\end{tabular}

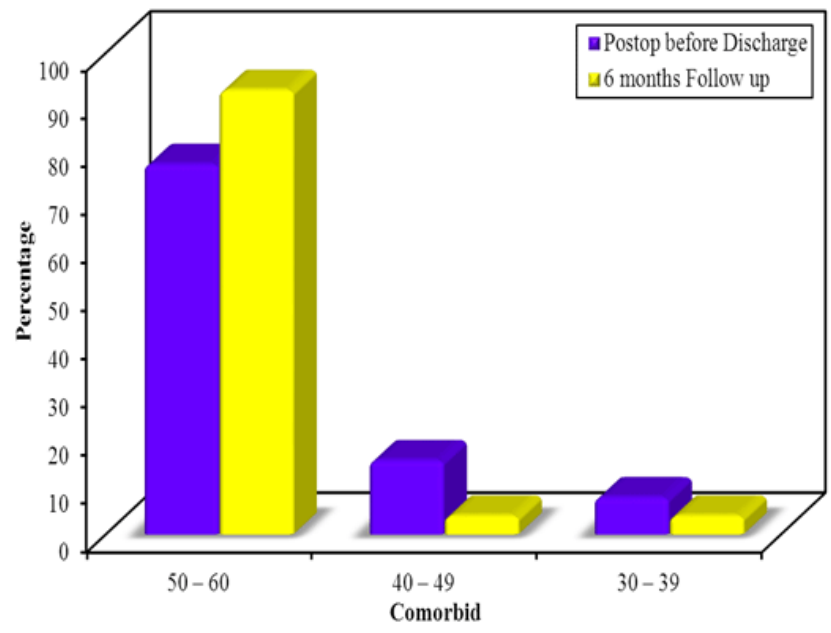

Figure 9: Postoperative and 6 Months follow up According of all patients acc. to group A

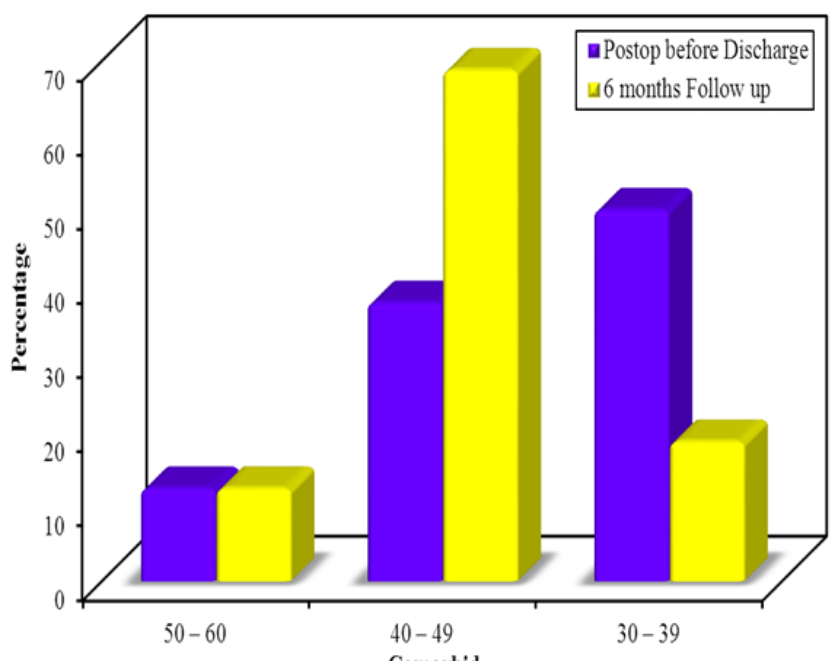

Figure 11: Postoperative and 6 Months follow up According of all patients acc. to group C

Table 11: Postoperative and 6 Months follow up According of all patients acc. to group

B

\begin{tabular}{|c|c|c|c|c|}
\hline \multirow{2}{*}{ Group B } & \multicolumn{2}{|c|}{ Postop before Discharge } & \multicolumn{2}{c|}{ 6 months Follow up } \\
\cline { 2 - 5 } & No. & \% & No. & \% \\
\hline $50-60$ & 5 & 38.46 & 4 & 30.77 \\
\hline $40-49$ & 7 & 53.85 & 9 & 69.23 \\
\hline $30-39$ & 1 & 7.69 & 0 & 0 \\
\hline
\end{tabular}




\begin{tabular}{|c|c|c|c|c|}
\hline \multicolumn{5}{|c|}{ C } \\
\hline \multirow[b]{2}{*}{ Group C } & \multicolumn{2}{|c|}{ Postop before Discharge } & \multicolumn{2}{|c|}{6 months Follow up } \\
\hline & No. & $\%$ & No. & $\%$ \\
\hline $50-60$ & 2 & 12.5 & 2 & 12.5 \\
\hline $40-49$ & 6 & 37.5 & 11 & 68.8 \\
\hline $30-39$ & 8 & 50 & 3 & 18.8 \\
\hline
\end{tabular}

and 6 months later; $13 \backslash 17$ patients showed increase EF while only $3 \backslash 17$ patients remained with EF between $30-39 \%$ (Table 12, Figure 11).

\section{Discussion}

Actually most of the literature is talking about the timing of the urgent surgery for revascularization of cases with significant LM coronary disease or significant LM equivalent but only a few articles were talking about the follow up and postoperative outcome of urgent CABG.

This attracted and encouraged us to do our study for follow up of these cases and to analyze their outcomes.

In our study patients were stratified into three groups according to EF A 50-60\%, B 40-49 \% , C 30-39\% while other authors considered EF below $40 \%$ as an independent risk factor for predicting the outcome after CABG surgery $[7,8]$.

The use of preoperative IABP in our study was in $6 \backslash 60$ patients $(10 \%)$ while with other authors this percentage climbed to approximately $~ 30 \%[7,9]$.

We shared the same methodology for patient choice as with most articles in the literature, ranging from 1-14 days according to number of cases and priority in wanting list as well as availability of surgical spots, our mean time for surgery was $4.3 \pm$ 1.86 days, the priority for surgery is discussed by cardiology and cardiac surgeons according to clinical status and angiography, some patient with intractable chest pain or critical anatomy are scheduled on operating list on the same day or next day, other patients scheduled according to priority and also dependent on triage status (incorporating clinical status) and operating room availability [9-12].

Many priority scales were applied in many studies, Ontario and New Zealand priority score are used to define priority [10]. The standard Time frame to urgent CABG varies depending on different reports, Kim et al [7] reported that most of his urgent cases done within 2- 8 hours from diagnosis, while Tomasco B, et al, [10] reported time from 1-3 days as urgent, Deyell et al, [11], consider 2-7 days as urgent also Naylor D, et al, [12] reported up to 14 days as urgent, we agreed to the consensus that all revascularization should be done in the same hospital admission..

In our study we observed long ventilation time $22.45 \pm 14.36$ hours with range from 6-168 hour, Chen Y, et al [13] reported lower ventilation hours with mean of 16 hours with range from (1-695) hours in the review of his cases.
In our study, Cholesterol levels above $200 \mathrm{mg} / \mathrm{ml}$ were considered as hyperlipidemia, total of 38 patients showed hyperlipidemia out of 58 patients as 2 patients were missed.

In our study post operative renal Dysfunction occurred in 2 cases which represents $3.4 \%$ of our cases, one case from group B and the other from group C, while in Kim A. Eagle et al [14] showed that Postoperative renal dysfunction occurs in as many as $7.7 \%$ of patients.

Renal dysfunction, defined as postoperative $\mathrm{SCr}$ of at least 2.0 $\mathrm{mg} / \mathrm{dL}$ accompanied by an increase of at least $0.7 \mathrm{mg} / \mathrm{dL}$ from preoperative baseline [15].

In our study 7 patient showed postoperative arrhythmias $11.6 \%$ of all cases, 5 patients had post operative AF were cordarone infusion started as a loading and then maintained and subsided pre-discharge without starting warfarin, 1 patient with SVT without HD instability, and 1 patient with persistent VF and died during the ICU stay.

In our study mortality was $5 \backslash 60$ patients (12\%) of all patients, 1 patient died intraoperative and 4 patient died during the ICU period, 4 patients was from group $C$ and 1 patient from group B, while the mortality in other studies like study of Kim and his co-authors they reported mortality of $17.3 \%(18 \backslash 104)$ and considered that EF less than $40 \%$ is a risk factor for mortality while Hirose H, et al [16] demonstrated (11\47) 23.4\% mortality in his group of urgent CABG and he considered that an ejection fraction $<50 \%$ is a risk factor for death after MI.

In our group all patient had LIMA and Saphenous vein graft only 6 patients had radial artery graft, $53 \%$ of patients underwent CABG with 3 grafts while $16 \%$ with 4 grafts and $12 \%$ with 2 grafts the number of grafts used didn't show significant difference between all groups. CPB time, AXC time, and total OR time were longer with group C; this mostly attributed to that many of our patients having difficulty to wean off bypass machine or required re-bypass again.

Generally our results in the same line with results of, Järvinen 0 , et al [17], which showed significant improvement in functional capacity and NYHA class during the 1st year after CABG.

We lost $5 / 60$ of our patient population representing about $8.3 \%$ mortality, 55 patients were discharged free of symptoms with a pre-discharge ECHO measurement of their ejection fractions as follows

For group A 26 patients initial EF 50-60\%, 4 had transient decrease of $\mathrm{EF}$ to become between $40-49 \%, 2$ patients $\mathrm{EF}$ temporary decreased to 30-39\% at pre discharge ECHO however at 6 months ECHO follow up all EF patients were between 50$60 \%, 1$ between $40-49 \%$ and another 1 between $30-39 \%$

As for group B 13 patients, initial EF 40-49\%, 5 had increase of EF to $50-60 \%, 7$ remained same as pre-op EF and 1 decreased to $30-39 \%$ and at 6 months follow up 9 patients remained at $40-$ $49 \%$ while 4 patients improved to $50-60 \%$

As for group C 16 patients with initial EF $30-39 \%, 2$ patients EF increased to $50-60 \%, 6$ increased to $40-49 \%$ while 8 remained at EF $30=39 \%$, at 6 months follow up 2 patients increased to $\mathrm{EF}$ $50-60 \%, 11$ patients improved EF to $40-49 \%$ and only 3 patients remained at $\mathrm{EF} 30-39 \%$ 
Aronson S, et al [18] showed that CABG surgery contributes to improved regional and global left ventricular function in patients with left ventricular dysfunction with or without angina and infarction. Revascularization of viable but dysfunctional myocardium perfused by markedly obstructed vessels can reduce the threat to the myocardium and improve left ventricular function. Furthermore, it has been demonstrated that up to $50 \%$ of patients with a previous infarction may have areas of hibernating tissue mixed with areas of scar tissue, even in the presence of Q waves on the electrocardiogram. Douki ZE, et al [19], they reported improving in functional status early and late after CABG even with elderly patients, at least on NYHA class improving at early period. Søraas C, et al [20] reported early improvement of myocardial contractility and improvement of WMSI. Most of these studies confirmed that the early improvement of contractility and WMSI associated with good long-term outcome, in contrary deterioration of WMSI early after CABG is associated with poor outcome as reported by Swaminathan M, et al [21].

\section{Conclusion}

Our study demonstrated that the patients undergoing Urgent CABG have a significant higher preoperative risk especially with myocardial impairment. Despite the higher mortality rate $8.3 \%$, a reasonable and favorable clinical outcome can be achieved when those patients tolerate the surgery and survive. Also we assume that establishing hemodynamic stability in conjunction with the cardiologist prior to surgery significantly influences the surgical outcome.

\section{Study limitations}

We can put on-hand on some limitations for this study such as:

The potential bias of any retrospective study and sometimes we couldn't get full detailed information from some patient's files (e.g. some operative details or missed post-operative follow up) that may affect the outcome so these patients were excluded from the study.

We also don't have information on the number of patients who may have not survived after presentation with significant LM lesion or LM equivalent and therefore never received a CABG.

Our study was done in two tertiary centers only, and may require bigger patient volume for more precise evaluation and statistical assessment.

\section{Acknowledgement}

The authors would like to acknowledge all the medical and nursing staff who has contributed to the data collection. Also we would like to thank cardiac surgeons and cardiologists who contributed in patients' management and we would like to thank the research center's staff for their contribution to this research and for their assistance with revising, and their contribution to conception, design and processing of this project.

\section{Author's contributions}

YS and MY wrote the studies, participated in the sequence alignment, drafted the manuscript and were in charge of overall direction and planning. MR and MS collected the data and carried out the statistics. AE and BM participated in the surgical part and conceived the presented idea. AG, ME, MA and AS participated in the design of the study and performed the statistical analysis. YS and $\mathrm{MH}$ conceived of the study, and participated in its design and coordination and helped to draft the manuscript.

SE, AE and YT helped supervise the project and shared in data collection and verified the analytical methods. AG, MA and MM contributed to the final version of the manuscript, supervised the project. All authors read and approved the final manuscript.

\section{References}

1. Virani SS, Mendoza CE, Ferreira AC, de Marchena E. Left Main Coronary Artery Stenosis: Factors Predicting Cardiac Events in Patients Awaiting Coronary Surgery. Tex Heart Inst J. 2006;33(1):2326.

2. Ragosta M, Dee S, Sarembock IJ, Lipson LC, Gimple LW, Powers ER. Prevalence of unfavorable angiographic characteristics for percutaneous intervention in patients with unprotected left main coronary artery disease. Catheter Cardiovascular Intervention 2006;68(3):357-362.

3. Weiss ES1, Chang DD, Joyce DL, Nwakanma LU, Yuh DD. Optimal timing of coronary artery bypass after acute myocardial infarction: a review of California discharge data. J Thorac Cardiovasc Surg. 2008;135(3):503-511. doi: 10.1016/j.jtcvs.2007.10.042

4. Abd-Alaal MM, Alsabban MA, Abbas OA, Alshaer AA, Al-Saddique A, Fouda M. Timing of Revascularization after Acute Myocardial Infarction. Asian Cardiovasc Thorac Ann. 2010;18(2):118-21. doi: 10.1177/0218492310361001

5. Mitsumasa Hata, Motomi Shiono, A Sezai, M Iida, et al. Outcome of Emergency Conventional Coronary Surgery for Acute Coronary Syndrome Due to Left Main Coronary Disease. Ann Thorac Cardiovasc Surg. 2006;12:28-31.

6. Monteiro P. Impact of Early Coronary Artery Bypass Graft in an Unselected Acute Coronary Syndrome Patient Population. Circulation. 2006;114(I)- :I467-:I472.

7. Kim D-K, Yoo K-J, Hong YS, Chang B-C, Kang M-S. Clinical Outcome of Urgent Coronary Artery Bypass Grafting. Journal of Korean Medical Science. 2007;22(2):270-276. doi:10.3346/jkms.2007.22.2.270

8. Chen Y, Almeida AA, Goldstein J, Shardey GC, Pick AW, et al. Urgent and emergency coronary artery bypass grafting for acute coronary syndromes. ANZ J Surg. 2006;76(9):769-773.

9. Christenson JT, Simonet F, Badel P, Schmuziger M. Optimal timing of preoperative intraaortic balloon pump support in high-risk coronary patients. Ann Thorac Surg. 1999;68(3):934-939.

10.Seddon M E, K French J, Amos D J, et al. Waiting times and prioritization for coronary artery bypass surgery in New Zealand. Heart. 1999;81(6):586-592 .

11. Tomasco B, Cappiello A, Fiorilliet R, Leccese A, Lupino R, Romiti A, et al. Surgical Revascularization for Acute Coronary Insufficiency: Analysis of Risk Factors for Hospital Mortality. Ann Thorac Surg. 1997;64(3):678-683.

12. Deyell MW, Ghali WA, Ross DB, et al. the Alberta Provincial Project for Outcome Assessment in Coronary Heart Disease (APPROACH) Timing of non emergent coronary artery bypass grafting and mortality after non-ST elevation acute coronary syndrome. Am Heart J. 2010;159:490-496. 
13. Kim A Eagle, Robert A Guyton, Ravin Davidoff, Fred H Edwards, Gordon A Ewy, Timothy J Gardner, et al. ACC/AHA 2004 Guideline Update for Coronary Artery Bypass Graft Surgery. Circulation. 2004;110(14):1168-1176.

14. Sarah C, Chirag R Parikh. Predicting Acute Kidney Injury After Cardiac Surgery: A Systematic Review, Ann Thorac Surg. 2012;93(1):337-347. doi: 10.1016/j.athoracsur.2011.09.010

15. Hirose H, Amano A, Yoshida S, Nagao T, Sunami H, Takahashi A, et al. Surgical management of unstable patients in the evolving phase of acute myocardial infarction. Ann Thorac Surg. 2000;69(2):425428.

16. Järvinen 0 , Saarinen T, Julkunen J, Huhtala H, Tarkka MR. Changes in health-related quality of life and functional capacity following coronary artery bypass graft surgery. Eur J Cardiothorac Surg. 2003;24(5):750-756.

17. Aronson S, Dupont F, Savage R, , Drum M, Gunnar W, Jeevanandam $V$. Changes in regional myocardial function after coronary artery bypass graft surgery are predicted by intraoperative low-dose dobutamine echocardiography. Anesthesiology. 2000;93(3):685692.
18. Alassal M, Elrakhawy H, Omar H, Hassenien M, et al. Comparison of clinical outcomes among patients undergoing CABG with or without prior PCI, journal of clinical and experimental cardiology. 2015:405. doi:10.4172/2155-9880.1000405.

19. Douki ZE, Vaezzadeh N, Zakizad M, Shahmohammadi S, Sadeghi R, Mohammadpour RA. Changes in functional status and functional capacity following coronary artery bypass surgery. Pak J Biol Sci. 2010;13(7):330-334.

20.Søraas CL, Larstorp AK, Mangschau A, Theis Tønnessen, Sverre E Kjeldsen, Reidar Bjørnerheima. Echocardiographic demonstration of improved myocardial function early after coronary artery bypass graft surgery. Interactive CardioVascular and Thoracic Surgery. 2011;2011(12): 946-951. doi:10.1510/icvts.2010.260414

21. Swaminathan M, Morris RW, De Meyts DD, Podgoreanu MV, Jollis JG, Grocott HP, et al. Deterioration of Regional Wall Motion Immediately after Coronary Artery Bypass Graft Surgery Is Associated with Long-term Major Adverse Cardiac Events. Anesthesiology. 2007;107(5):739-745. 